\title{
Pseudopelade of Brocq: a clinico-therapeutic challenge!
}

\author{
S Jain \\ Department of Skin and VD, MGIMS, Sewagram \\ Wardha, Maharashtra, India
}

\begin{abstract}
Pseudopelade of Brocq is a clinical syndrome comprising of scarring alopecia and fibrosis in which distinct pathological features are absent. It is not a specific disease, rather a pattern of cicatricial alopecia. However, if a definitive diagnosis of DLE (discoid lupus erythematosus), LPP (Lichen planopilaris) or any other condition can be made on the basis of clinical, histopathological or immunofluorescent features, then this term cannot be used. Here we report the case of a 20 year old young male who presented to us with complaints of loss of scalp hair for 2 years which were associated with mild itching. The condition is as such rare in prevalence and hence we report the same in view of its unique presentation.
\end{abstract}

Keywords: Pseudopelade of Brocq, scarring, alopecia, cicatricial alopecia

\section{Introduction}

Pseudopelade of Brocq is an idiopathic, chronic, slowly progressive, patchy cicatricial alopecia ${ }^{1}$ that occurs without any evidence of inflammation. ${ }^{2}$ It is an atrophic rather than an inflammatory folliculitis. The term pseudopelade was first used by a French dermatologist Louis-Anne-Jean Brocq, to distinguish this condition from the pelade of alopecia areata. Pelade is derived from a french word 'pelage' meaning the fur, hair, wool etc of mammal. ${ }^{3}$ However, it has been accepted that the condition is the end result of follicular fibrosis caused by a primary inflammatory dermatosis such as lichen planus, lupus erythematosus, pustular scarring forms of folliculitis or fungal infections like favus, scleroderma and sarcoidosis. ${ }^{4}$ Braun-Falco et al proposed the diagnostic criteria for pseudopelade of Brocq on the basis of clinical, histopathological and immunoflorescence features. ${ }^{1}$

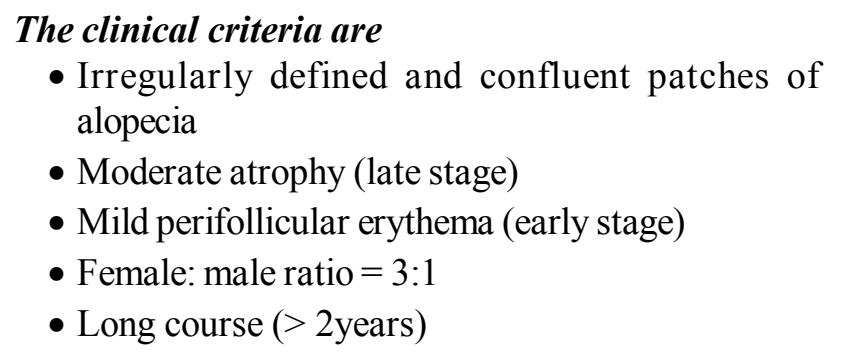

Address for Correspondence

Dr Sonia Jain

Professor, Department of Skin and VD, MGIMS, Sewagram

Maharashtra

Email: soniapjain@rediffmail.com
- Slow progression with spontaneous termination possible.

\section{Histopathological criteria ${ }^{5}$}

- Absence of marked inflammation

- Absence of widespread scarring (best seen with elastin stain)

- Absence of significant follicular plugging

- Absence or at least a decrease of sebaceous glands

- Presence of normal epidermis (only occasional atrophy)

- Fibrotic streams into the dermis

\section{Direct Immunofluorescence}

- Negative (or only weak Ig M on sun exposed skin)

The atrophic patches have been likened to footprints on snow' kind of appearance. ${ }^{5}$

\section{Case report}

Here we report the case of a 20 year old male who presented to us with scarring alopecia over the parietal lobes bilaterally. He had these complaints for the past two years and it was associated with mild itching over the bald areas. The hair loss were insidious in onset and gradually progressive since then and he had not consulted any dermatologist for the same. The patches were smooth, soft and slightly depressed with an oval contour and ranged in size from $1 \mathrm{~cm}$ to $2 \mathrm{~cm}$. The hair at the edges of the patches were easily pluckable. The hair in the region of the uninvolved scalp were 
normal. He had no axillary or pubic hair loss. There were no skin lesions elsewhere on his body and neither did he complain of any mucosal lesions. There were no associated systemic complains either.

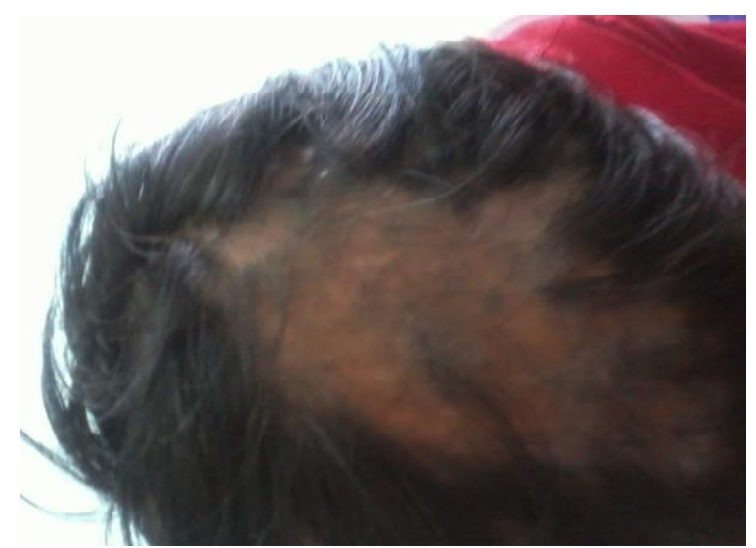

Figure 1: Showing bald patches over the vertex

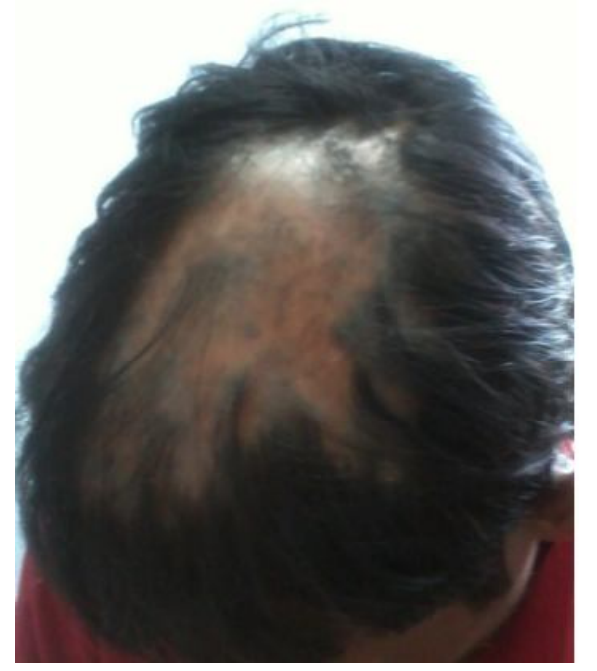

Figure 2: Showing the characteristic 'foot prints on snow' appearance over the vertex

\section{Discussion}

There is paucity of data on the aetiology and effective treatment of cicatricial alopecia worldwide. ${ }^{6}$ Pseudopelade of Brocq may occur in both sexes and at any age. The inflammatory process predominantly occurs around the permanent portion of the hair follicle i.e the stem cells of the bulge area and the infundibulum, thus accounting for the irreversibility of the condition. ${ }^{7}$ There is a hypothesis proposed to explain the pathogenesis of the condition which states that the stem cells of the follicle reside in the isthmus rather than the matrix and this explains that the stem cell damage can lead to permanent hair loss. ${ }^{8}$ Pseudopelade of Brocq has been reported to be one of the commonest causes of cicatricial alopecia as reported by Whiting et al. ${ }^{9}$ Histopathologially, using an acid alcohol orcein stain, elastic fibres are seen around the lower part of the follicle in this condition, while in all other scarring alopecias, the scar tissue consists of collagen devoid of elastin. ${ }^{2}$ There is one school of thoughts that this condition is caused by lichen planus on the basis of associated skin lesions and histopathological findings. ${ }^{10}$ The alopecia is asymptomatic and is often discovered by chance. It always remains confined to the scalp. The treatment is extremely difficult as the condition is largely irreversible. The response to topical or intra lesional steroids per se is also very poor. Our patient was also given intralesional triamcinolone acetonide (diluted to $5 \mathrm{mg} / \mathrm{ml}$ and injected with a tuberculin syringe) at an interval of 4 to 6 weeks. It was given for three cycles at the interval of every 4 to 6 weeks but without any positive response. The condition did not respond to any modality to stop its progression and ultimately we had to stop the treatment.

However in case of extreme disfigurement, autografting ${ }^{11}$ from the unaffected scalp can be considered, provided there is no active inflammation. Surgical expansion techniques have been suggested but have rarely stood the test of time. Also, off late antimalarials, antifungals or retinoids have been tried but with limited success. ${ }^{12}$ Hence as of now there is no definite management to halt the decease progression, which remains a challenge to the treating dermatologist.

\section{References}

1. Sperling LC. Brocq's alopecia (pseudopelade of Brocq) and "burnt out" scarring alopecia. In: Sperling LC, ed. An Atlas of Hair Pathology: With Clinical Correlations. London, England: Parthenon; 2003:115-8.

2. Braun-Falco, Imei $\mathrm{S}, \mathrm{Schmoeckel} \mathrm{C}$ et al. Pesudoplade of Brocq. Dermatologica 1986; 172: 18-26.

3. D.A.R de Berker, R. Baran \& R.P.R Dawber. Disorders of nails. In: Tony Burns, Stephen Breathnach, Neil Cox et al, editors. Rook's textbook of dermatology. $7^{\text {th }}$ edn. Massachusetts: Blackwell; 2004. p 63.53

4. Mark R. Pittelkow, Mazen Daoud. Lichen Planus. In. Klaus Wolff, Lowell A. Goldsmith, Stephen I. Katz et al, editors. Fitzpatrick's dermatology in general medicine. $7^{\text {th }}$ edn. New York: Mc Graw Hill; 2003. p 248 
5. Headington JT. Cicatricial alopecia. Dermatol Clin 1996; 14: 773-82

6. Olsen E, Bergfeld W, Cotsarelis G, Price V, Shapiro $\mathrm{J}$, Sinclair R, et al. Summary of North American Hair Research Society (NAHRS)- sponsored workshop in cicatricial alopecia. J Am Acad Dermatol 2003; 48:103-10.

7. Tan E, Martinka M, Ball N, Shapiro J. Primary cicatricial alopecias: Clinicopathology of 112 cases. J Am Acad Dermatol 2004; 50:25-32.

8. Sun TT, Cotsarelis G, Lavkar RM, hair follicular stem cells: the bulge activation hypothesis. J Invest Dermatol. 1991; 96: 77S- 78S
9. Whiting DA. Ciacatricial alopecia: Clinicopathological findings and treatment. Clin Dermatol 2001; 19:211-25.

10. Gay Prieto J. Pseudopelade of Brocq: its relationship to some forms of cicatricial alopecia and to lichen planus. J Invest Dermatol 1955; 24 : 323-34.

11. Stough DB, Berger RA, Orentriech N. Surgical improvement of cicatricial alopecia of diverse etiology. Arch Dermatol 1968; 97: 331-5.

12. Wilma F. Bergfeld. Disorders of nails. In. Samuel L. Moschella, Harry J. Hurley, editors. Dermatology. $3^{\text {rd }}$ ed. Philadelphia: W.B Saunders; 1992. p 1548 